\title{
1 Rapid speciation and karyotype evolution in Orthoptera
}

2

3 Octavio M. Palacios-Gimenez ${ }^{1,2}$

4

$5{ }^{1}$ Department of Organismal Biology - Systematic Biology Program, Evolutionary Biology Centre,

6 Uppsala University, SE-752 36, Uppsala, Sweden

$7 \quad{ }^{2}$ Population Ecology Group, Institute of Ecology and Evolution, Friedrich Schiller University Jena, 807743 Jena, Germany.

10 Correspondence: Octavio M. Palacios-Gimenez

11 Department of Organismal Biology - Systematic Biology Program, Evolutionary Biology Centre,

12 Uppsala University, SE-752 36, Uppsala, Sweden

13 Population Ecology Group, Institute of Ecology and Evolution, Friedrich Schiller University Jena, 1407743 Jena, Germany.

16 Email: octavio.palacios@ebc.uu.se (O.M.P.G) 


\section{Abstract}

27 To test the hypothesis that high speciation rate in groups is coupled with high rate of karyotype

28 evolution but also that younger groups having a higher rate of karyotypic diversity, I estimated

29 rates of speciation and rates of karyotype evolution in 1,177 species belonging to 26 families in

30 the insect order Orthoptera. Rates of karyotype evolution were estimated using the diploid number

31 and the number of chromosome arms (fundamental number) from published karyotypes of

32 Orthoptera. Rates of speciation were quantified considering the number of species examined

33 karyotypically in each family, the most recent common ancestor of each family and the information

34 about extinction rate. The rate of speciation was strongly correlated with rate of karyotype

35 evolution and the average rates of speciation was nearly $\sim 177$ times higher than the background

36 rate estimated for Orthoptera based on acoustic communication using phylogenomic data, as well

37 as 8.4 and 35.6 times higher than the estimated speciation rate in vertebrates and bivalve mollusks

38 respectively, indicating that Orthoptera has evolved very fast at chromosomal level. The findings

39 supported the hypothesis of a high speciation rate in lineages with high rate of chromosomal

40 evolution but there were not evidences that younger groups tended to have higher rate of

41 karyotypic diversity. Furthermore, rates of karyotype evolution most closely fitted the

42 punctuational evolutionary model indicating the existence of long periods of stasis of karyotype

43 change with most karyotype change occurring quickly over short evolutionary times. I discussed

44 genetic drift, divergent selection and meiotic drive as potential biological mechanisms to explain

45 karyotype evolution allowing or impeding for the fixation of chromosomal rearrangements and in

46 turn speciation in orthopterans lineages.

47 Keywords: karyotypic change, evolution, speciation, Orthoptera 
Introduction

The link between karyotype evolution and speciation have long been a topic of heated debate among evolutionary biologists (White 1978; Sites and Moritz 1987; Coyne and Allen Orr

51 1998; Hoffmann and Rieseberg 2008). Earliest hypothesis pointed out that small populations are

52 essential for quick speciation (Wright 1931, 1940; Mayr 1970; Coyne and Allen Orr 1998). Under

53 this view, a new species might arise when a small subset of individuals isolated from a large

54 population establish a new colony (bottleneck or founder effect) or small demes maintained by

55 social structuring and ecology (Coyne and Allen Orr 1998; Hoffmann and Rieseberg 2008). It is

56 also widespread acceptance of the hypothesis that small population are critical for karyotypic

57 evolution suggesting that speciation and karyotypic change may likely be associated (White 1978;

58 Coyne and Allen Orr 1998; Hoffmann and Rieseberg 2008). It is not easy to obtain direct evidence

59 of the relationship between population size and rate of evolution because estimates of population

60 size is restricted only to a few number of taxa across the Tree of Life. However, it is possible to

61 examine quantitatively the relationship between karyotype evolution and speciation in taxa with

62 well-described karyotypic information. Rates of karyotypic change and speciation might be

63 associated if both factors depend on the occurrence of small population.

The link between karyotypic change and speciation was qualitatively examined in groups

65 of organisms like mammals (Bush et al. 1977), birds (Tegelström et al. 1983), fishes (Yoshida and

66 Kitano 2021) and bivalve mollusks (Stanley 1975), that has led to a heated debate (King 1985;

67 Sites and Moritz 1987). Opinions differ as to the relationship between karyotypic changes and

68 speciation, these changes being considered by some as causative of reproductive isolation and in

69 turn speciation (White 1978; King 1995), and by others as an incidental by-products of speciation 
70 processes (Coyne 1984) devoid of any effect on speciation (Futuyma and Mayer 1980;

71 Charlesworth et al. 1982).

72 Many models of karyotypic changes have been suggested over the past 70 years (Rieseberg

73 2001). The canalization model (Bickham and Baker 1979) suggested that karyotypic change

74 diversification in younger groups of vertebrates (e.g. rodents) is higher than in older groups of

75 vertebrates (e.g. bats and turtles). This model, however, has been widely criticized because is

76 difficult to test and when prediction were made, empirical evidences do not support the model (see

77 King 1985; Sites and Moritz 1987). The most widely accepted models of karyotypic changes

78 concern the effect of individual chromosomal rearrangements that decrease the fertility of the

79 heterozygotes by either disrupting the segregation pattern in meiosis or reducing the recombination

80 rate in rearranged areas of the genome. Some of the most prominent models within this category

81 differ in both geographic context and in the manner in which new rearrangements are spread once

82 fixed. The stasipatric model (White 1978) assumes that a strongly underdominant chromosomal

83 rearrangement arises and becomes fixed in a population that is within the range of the progenitor.

84 The chain or cascade model (White 1978) alleges that reproductive isolation result from the

85 accumulation of chromosomal rearrangements that are individually underdominant. The

86 chromosomal transilience model (Templeton 1981) states that a strongly underdominant

87 chromosomal rearrangement might be fixed by drift and endogamy in an isolated population.

88 Substantial isolating barrier with respect to the ancestral karyotype might complete speciation. The

89 quantum speciation model (Grant 1981) proposes that chromosomal rearrangements become fixed

90 very quickly in a peripheral founder population by drift and endogamy promoting reproductive

91 isolation. This model is similar to the chromosomal transilience model except that the new gene

92 arrangement resulting from the karyotypic change are thought to be adaptive. The monobraquial 
93 fusion model (Baker and Bickham 1986) alleges that different centric fusions become

94 independently fixed in isolated subpopulation; the fusions might then cause little or no loss of

95 fertility on heterozygote individuals. Hybrids between the two subpopulation, however, would be

96 intersterile because different combination of chromosomal arms had been fused in the two

97 subpopulation. Finally, the recombinational model (Lewis 1966) states that hybridization between

98 chromosomal divergent population leads to chromosomal breakages and to the sorting of

99 preexisting rearrangements that differentiate from the parental species. The tenets against these

100 models in speciation are: 1) the observation that most chromosomal rearrangements have little

101 effect on fertility (Dobzhansky 1933; Sites and Moritz 1987; Coyne et al. 1993), 2) theoretical

102 difficulties related to fixing chromosomal rearrangements that are strongly underdominant (i.e.

103 reduce the fitness of heterozygotes) (Walsh 1982; Lande 1985), 3) the supposed ineffectiveness of

104 chromosomal rearrangements to impede gene flow (Barton 1979; Futuyma and Mayer 1980;

105 Spirito, F. 2000), and 4) the widespread acceptance of the idea that premating and/or ecological

106 barriers predate chromosomal rearrangements in the speciation process and thus may likely cause

107 speciation (Coyne et al. 1993; Schluter, D. 1998; Schemske 2000). Much more work is thus needed

108 to test the generalities of these chromosome-based speciation models.

110 species of the insect order Orthoptera to investigate two central goals: rates of karyotypic change

111 and speciation in Orthoptera. Rates of karyotypic change was strongly correlated with rate of

112 karyotype evolution. Both rates varied largely in these animals being an order of magnitude in

113 most orthopterans higher than vertebrates and bivalve mollusks. Therefore, it was essential to

114 estimate both rates in a wide variety of orthopterans. The result of such estimates reported bellow

115 were discussed in the light of genetic drift, divergent selection and meiotic drive as potential 
116 biological mechanisms to explain karyotype evolution and in turn speciation in orthopterans

117 lineages.

\section{Methods}

\section{Rates of karyotype evolution}

I compiled information on diploid number (2n) and number of chromosome arms

122 (fundamental numbers, FN) from males in 1,177 orthopteran species belonging to 25 families (Fig.

123 1), based on published data from the literature (Supplementary Table S1). The compiled data

124 concerned families of long-horned grasshoppers (suborder Ensifera) and short-horned

125 grasshoppers (suborder Caelifera), and therefore, covered the Orthoptera Tree of Life. Only diploid

126 species were considered. Polymorphic species for diploid numbers were taking into account. B

127 chromosomes were not considered. Utilising this information, I estimated the rates of karyotype

128 evolution $\left(r^{\prime}\right)$ within a major taxonomic group (i.e., family) following the equation proposed

129 elsewhere (Bush et al. 1977):

$$
r^{\prime}=\sum_{i=1}^{K S}\left(a_{i}+b_{i}\right) / \sum_{i=1}^{K S} t_{i}
$$

131 in which $K S$ is the number of species examined karyotypically within a family, and $t$ is the

132 divergence time of the most recent common ancestor of a family in the fossil record (Song et al.

$1332015,2020)$ in millions of years ago (Myr). The symbol $a$ was defined as $(c-d) / K S$, in which $c$

134 stands for the highest diploid number and $d$ for the lowest diploid number within the family.

135 Likewise, $b$ was defined as $(e-f) / K S$, in which $e$ stands for the highest FN and $f$ for the lowest FN.

136 Thus, the rate quantifies karyotypic changes/per lineages per million years. The method deals with

137 chromosomal rearrangements like fusions/fissions and pericentromeric inversions that alter

138 chromosome number and the FN, respectively. However, it doesn't deal with most micro- 
139 chromosomal rearrangements (e.g. paracentric inversions) and chromosomal reciprocal

140 translocations that might be critical for karyotype evolution, reproductive isolation and in turn

141 speciation. The latter mutations are usually detected in vertebrates through chromosome painting

142 and chromosome banding techniques, but unfortunately, this information is not available in the

143 orthopterans cytogenetic literature because it is difficult to recognize through classical cytogenetic

144 methods, and therefore, these mutations were not taking into account.

\section{Rates of speciation}

149 and $E$ stands for the average rate at which species have become extinct over a defined period of

150 time. The mean value of the $R$ was estimated for each family of Orthoptera following the equation

151 described elsewhere (Bush et al. 1977):

$$
R=\sum_{i=1}^{K S} h_{i} / \sum_{i=1}^{K S} t_{i}
$$

153 in which $K S$ is the number of species examined karyotypically within a family, and $h$ stands for

154 the number of speciation events per lineage. Therefore, the $h$ values were summed and divided by 155 the summed time range $(t)$ for the family. The $h$ values were estimated by using the following 156 equation (Bush et al. 1977):

$$
h=\frac{g+1}{2}-\frac{1}{g}
$$

158 in which $g$ stands for the number of existing species per family obtained from the literature (Song

159 et al. 2015; Cigliano et al. 2021). 
To estimate the average extinction rate $(E)$ for species within the family, I first looked back

161 in geological time to find strata in which $50 \%$ of the family fossils belong to extant species. The

162 time was then designed $D / 2$, in which $D$ was defined to an estimate of the species duration for

163 species in that family. The mean extinction rate $(E)$ was then defined to be 1/D (Stanley 1975;

164 Bush et al. 1977). Divergence time were obtained from the fossil record available in the literature

165 (Song et al. 2015, 2020). Finally, I got an estimate of $S$ (referred to as the corrected speciation rate)

166 for each family by adding the $E$ and $R$ values. All of the statistical analysis were ran in $\mathrm{R}$ version

$167 \quad 3.5 .1$ (R Core Team 2018).

\section{Results}

The $2 \mathrm{n}$ across males of Orthoptera varied from 7 in Eunemobius carolinus carolinus

171 (Trigoniidae) to 57 in Diestrammema tachycines asynamorus (Rhaphidophoridae), while the NF

172 varied from 11 in Strinatia brevipenis (Phalangopsidae) and Gryllacris signifera (Gryllacrididae)

173 to 64 in Dolichopoda schiavazzii (Rhaphidophoridae) (Fig. 1, Supplementary material 1). The

174 karyotype diversity (Shannon index, $H^{\prime}$ ) estimated from the FN varied from 0 (Mogoplistidae,

175 Schizodactylidae, Ripipterygidae) to 6.341 (Tettigoniidae). The karyotypic changes/per lineages

176 per million years $\left(r^{\prime}\right)$ estimated for all of the families analysed appear in Table 1. A linear

177 regression indicated that $r^{\prime}$ is determined by the percentage of $K S$ per family $(P=0.0107)$,

178 indicating that in the collected data set this mutation rate is sensitive to sampling bias. Thus, $r$ ' in

179 families with lower $K S$ were likely underestimated. The highest $r$ ' occurred within Tettigoniidae 180 and within the recent-divergent lineages Gryllidae, Phalangopsidae, Acridiade, Romaleidae and

181 Ommexechidae, indicating that orthopterans have evolved very fast at chromosomal level. 

lowest net of speciation $(R)$ occurred in Tridactylidae and Cylindrachetidae and the highest one in Acrididae, Gryllidae and Tettigoniidae . Extinction rate $(E)$ was lower on average in Orthoptera than in mammals and birds. Consequently, the corrected rates of speciation $(S)$ were substantially higher in Orthoptera than in vertebrates. Acrididae, Gryllidae and Tettigoniidae experienced

187 substantially high $S$ compared to the other families. To test whether high speciation rate in groups is coupled with high rate of karyotype evolution, I plotted $S$ against $r$ ' for the analysed group of

189 Orthoptera (Fig. 2). A linear regression indicated that $S$ is determined by the percentage of $r$ ' per 190 family $(P=0.00596)$. In other words, families with higher $r$ ' experienced higher $S$, e.g. 191 Tettigoniidae, Gryllidae, Acrididae.

\section{Discussion}

The results obtained highlight the existence of a general correlation between karyotypic changing rate and speciation rate in Orthoptera. Rapid karyotypic evolution in Orthoptera (average 0.367 events/lineage per Myr) compared to Polyneoptera insects (average 0.003-0.128) (Sylvester

197 et al. 2020), vertebrates (average 0.166) (Bush et al. 1977; Yoshida and Kitano 2021) and non198 passerine birds (average 0.167) (Tegelström et al. 1983) was supported by the high number of 199 species with dissimilar karyotypes. Remarkably, the average karyotypic change reported here was 200122 times higher than what has been recently reported in Orthoptera (average 0.003) (Sylvester et 201 al. 2020). This difference is likely owing to the higher number of sampled species in this study, 202 and because ii) the previous report only considered the variation in $2 \mathrm{n}$ to estimate the karyotypic 203 changes. It was therefore essential the increasing of the number of sampled species and the 204 compiling of FN to get a better estimation of the karyotypic change in Orthoptera. 
Importantly, there were not evidences that younger groups tended to have higher rate of karyotypic changes as alleged by the canalization model (Bickham and Baker 1979). On the contrary, I have observed the reverse pattern alleged by this model: younger group like Gryllidae

208 (divergence time <98 Myr) and the modern grasshoppers like Acrididae, Romaleidae (divergence

209 time $<80 \mathrm{Myr}$ ) and Ommexechidae (divergence time $<77 \mathrm{Myr}$ ) had lower rate of karyotypic 210 change than older group like Tettigoniidae (divergence time $\sim 154 \mathrm{Myr}$ ). Furthermore, Orthoptera

211 seemed to have limited extinction rate across its Tree of Life. The higher speciation rate observed 212 in Acrididae, Gryllidae and Tettigoniidae can be accepted as a satisfactory measures of the 213 evolutionary success of these groups. Acrididae grasshoppers represent one of most recently 214 diverged lineages within Orthoptera (Song et al. 2020) and seemed to have radiated quickly with 215 comparably higher speciation rate than other orthopterans, with little or no extinction similar to 216 that observed in the oldest Tettigoniidae. Importantly, Acrididae, Gryllidae and Tettigoniidae 217 seems not only to have a comparably high rate of changes in number of chromosomes but also a 218 comparably high number of centric fusions and pericentromeric inversions, indicating that these 219 genomes have high potential for change while the others remained frozen in time, in agreement 220 with the punctuational evolutionary model (Eldredge and Gould 1972). Therefore, centric fusions

221 and pericentromeric inversions played a critical role in karyotype reshuffling as demonstrated by

222 the reduction in male $2 \mathrm{n}$ and in male FN variation. Among these, centric fusions tend to be the 223 most common rearrangements. Fissions rate were reported to be lower in Orthoptera (average 224 0.024) compared to Polyneoptera insects (average 0.063-0.150) (Sylvester et al. 2020) most likely 225 because of the ineffectiveness of chromosomes to form or assemble new centromeric structures 226 essential for the proper chromosome segregation during cell divisions (Barra and Fachinetti 2018). 
But why were the centric fusions the most common large-scale chromosomal rearrangements in Orthoptera? In general, Orthoptera has very large (9 Gb on average; (Gregory 2021)) and repeat-enriched genomes mostly because the expansion of repetitive sequences, 230 ranging from 33 to 75\% per genome assembly (Palacios-Gimenez et al. 2020a; Ylla et al. 2020).

231 Chromosomal rearrangements might essentially depend on these repeated sequences that are

232 recombination hot spots in groups with high recombination rates such as rodents having large 233 portion of repeats in pericentromeric regions promoting chromosomal rearrangements (Bailey et 234 al. 2004). In Orthoptera, pericentromeric regions are heterochromatic and very enriched of highly235 homogeneous satellite DNA sequences (Ruiz-Ruano et al. 2016; Milani et al. 2018; Palacios236 Gimenez et al. 2020b) while transposable elements (TEs) are mostly scattered in the euchromatin 237 of chromosomes, as demonstrated by in situ hybridization (Montiel et al. 2012; Palacios-Gimenez 238 et al. 2014; Martí et al. 2021). The divergent pattern concerned the location of satellite DNA and 239 TEs might likely be an indication that of karyotypic intrinsic characteristics (e.g. heterochromatin 240 and satDNA localization) modulate chromosomal fusions; however this idea was never tested in

241 Orthoptera. If this hold true, it might be possible that centric fusions dependent on satellite DNA 242 sequences (White 1978; Dover 2002), although the determinant factors allowing or impeding the

243 fixation of karyotypic changes will be natural selection, genetic drift and/or meiotic drive (see

244 below). It might also be possible that repetitive DNA other than satellite DNA (e.g TEs) promotes

245 micro-structural rearrangements (e.g. deletions and insertions), paracentric inversions and 246 chromosomal reciprocal translocations by non-homologous recombination that might be critical 247 for karyotype evolution, reproductive isolation and in turn speciation. These kind of mutations 248 remained undetectable under the methodology used here. High-quality chromosome-scale 
assemblies with in-depth repeat and gene annotation not yet available for orthopterans are important steps ahead to provide accurate description of these kind of mutations in Orthoptera.

252 be promoted by less vagility in some species and consequently by the formation of reproductively

253 isolated demes also in the absence of geographical separation. The brachypterus South American

254 Melanoplinae grasshopper Dichroplus silveiraguidoi (male 2n=8, neo-XY, FN=13) form but one

255 example of the extreme divergence from the modal $2 \mathrm{n}$ and $\mathrm{FN}$ in Acrididae grasshoppers, in which

256 the karyotype have been largely rearranged by centric fusions that involved autosome-autosome

257 and autosome-X chromosomes (Saez 1957; Saez and Perez-Mosquera 1977). The flightless

258 Australian Morabidae grasshoppers in which the karyotypes have been largely reshuffled (male $2 \mathrm{n}$

259 from 14 to 19) by chromosomal rearrangements represent an example of extensive karyotype

260 variation in a parapatric distribution pattern, and narrow hybrid zones at their boundaries. (White

261 1978; Kawakami et al. 2009). Among long-horned grasshoppers, the cricket Eneoptera

262 surinamensis (male $2 \mathrm{n}=9$, neo- $\mathrm{X}_{1} \mathrm{X}_{2} \mathrm{Y}, \mathrm{FN}=17$ ) (Palacios-Gimenez et al. 2015) restrict to

263 Southern America and Northern South America (Cigliano et al. 2021), represent an example of the

264 extreme divergence from the modal 2n and FN in Gryllidae (see Fig. 1). To my knowledge, there

265 is not such karyotypes divergence in orthopterans with either great flight capacity or global

266 distribution, apart from the South American grasshopper Dichroplus pratensis (restricted to

267 Argentina, Uruguay and Southern Brazil) which is polymorphic and polytypic for a system of

268 centric fusions (Bidau and Martí 2002). Fixation of multiple centric fusions and consequently

269 greater karyotype divergence in the species abovementioned might have been favored by its less

270 vagility. Furthermore, multiple chromosomal mutations might have impeded genic introgression

271 via hybridization between species that differentiated by allopatry in agreement with the model of 
272 chromosomal primary allopatric speciation (King 1995). If this hold true, the fixation of the

273 multiple centric fusions might have predated the genetical and morphological differences (King

274 1995). Cases of species differentiating allopatrically have been documented in reptiles, in which

275 genic introgression in cases of secondary contact with the parental species was impeded by

276 chromosome differences (King 1995).

277 Though karyotypic changes are not a condition for speciation, it is widespread acceptance

278 that karyotypic change may contribute to the establishment of reproductive isolation favoring the

279 differentiation of incipient species (Faria and Navarro 2010). But how karyotypic changes may

280 become fixed in populations leading to differentiation and in turn speciation? White (White 1978)

281 alleged four factor that acting separately or combined might have influence in the incorporation of

282 a chromosomal variant in populations: genetic drift, meiotic drive, selective advantage of the

283 homokaryotype and inbreeding. The local chromosomal characteristic may diverge from the

284 parental condition by the action of either adaptation or genetic drift. It is widespread acceptance

285 that different environments produce differential selective pressure. Hence, if a karyotypic change

286 confers an adaptative advantage to carriers in a given condition, it might likely spread and

287 eventually become fixed in a population (Kirkpatrick and Barton 2006; Hooper and Price 2015).

288 Furthermore, species with patchy distribution and small demes may favor the chance of fixation

289 of the rearranged chromosomes by genetic drift, although gene flow between population will be

290 the major factor determining the fixation of local adaptive traits (Hooper and Price 2015). Lowly

291 vagile species like the brachypterous $D$. silveiraguidoi tends to have few migrants between

292 populations and, and consequently, a higher probability of fixation of adaptive traits. In addition,

293 if the selective pressure on the rearranged chromosome is very strong it might even become fixed

294 in the presence of gene flow (Coyne and Orr 2004; Kawakami et al. 2009). This may be the case 
295 of centric fusions and pericentromeric inversions having pronounced effect on meiotic

296 recombination by protecting coadapted alleles (supergenes) or by distorting the laws of Mendelian

297 inheritance (meiotic drive) that can be beneficial for the carriers in certain conditions (Bidau et al.

298 2001; Avril et al. 2020). Under this view, a global geographical distribution of families like

299 Tettigoniidae Gryllidae, Acrididae might expose its species to different selective pressures

300 allowing the fixation of different chromosomal rearrangements in different conditions.

301

However, it is also widespread acceptance that most chromosomal rearrangements are

302 either not adaptative (Hoffmann and Rieseberg 2008; Faria and Navarro 2010) or have little effect

303 on fertility (Sites and Moritz 1987; Coyne et al. 1993). However, for this to happen is essential

304 that populations with different combination of rearranged chromosomes are isolated

305 geographically (Lande 1985). The theoretical prediction is that population are more prone to

306 diverge genetically in allopatry, and under certain conditions, to accumulate chromosomal

307 rearrangements (Faria and Navarro 2010). Populations are prone to differentiate in the peripheral

308 areas of the distribution of the species because they have the chance to colonize and exploit new

309 habitats or niches (Bush et al. 1977). If an underdominant or neutral chromosomal rearrangement

310 arises under this condition, the rearranged chromosome in that population might differentiates and

311 expands if they are geographically isolated concerned to the parental population (Wright 1949;

312 Lande 1985). On the contrary, they will coalesce with the more numerous parental population via

313 hybridization, eventually the new mutation will be lost quickly because the lack of adaptative

314 advantage that might allow its permanence (Hoffmann and Rieseberg 2008). Again, low-vagility

315 species might favor this diversification mechanism because this condition might allowed exclusive

316 variants to become isolated and fixed in different localities, leading to speciation. The highest rates

317 of karyotypic change and speciation found in Acrididae, Gryllidae and Tettigoniidae are perfect to 
318 test this ideas. Among these, the South American Melanoplinae (Acrididae) grasshoppers might

319 be the most suitable species because of their disproportionate frequency of rearranged karyotypes

320 derived from centric fusions than other orthopterans (Castillo et al. 2010).

321 In summary, it was essential to estimate rates across the Orthoptera Tree of Life. The

322 findings showed that karyotype evolution mediated by chromosomal rearrangements strongly

323 correlates with speciation rate, likely indicating that karyotype evolution is not neutral. I further

324 showed that speciation rate is in-order-of-magnitude higher than vertebrates and bivalve mollusks,

325 and nearly 177 times higher than the estimated background rate of Orthoptera based on acoustic

326 communication using phylogenomic data (Song et al. 2020). Chromosomal rearrangements like

327 centric fusions are very common in Orthoptera. Centric fusions might have substantial and

328 immediate evolutionary impact by reducing genetic diversity in rearranged areas of the genome

329 likely reflecting increased background selection and selection against introgression between

330 diverging small demes or population, following a reduction in recombination rate. I also provided

331 evidences that karyotype evolution in Orthoptera most closely fitted the punctuational model of

332 evolution indicating the existence of long periods of stasis of karyotype change with most

333 karyotype change occurring quickly over short evolutionary times. Finally, the rapid karyotypic

334 changes in Orthoptera suggest that this taxa is a treasure box for studying the implication of

335 chromosomal rearrangements in evolution and speciation, and deserves more attention in this

336 respect.

$338 \quad$ Ethics

339 Not applicable. 


\section{Conflict of interest}

342 The author declare that there is not conflict of interest.

344 Funding

345 The work was supported by the Swedish Research Council Vetenskapsrådet (grant number 2020346 03866).

347

\section{Data accessibility}

349 The datasets generated as part of the study are available as supplementary information.

\section{Acknowledgements}

352 The manuscript was improved by comments from Diogo C. Cabral-de-Mello. Computations were 353 performed on resources provided by the Swedish National Infrastructure for Computing (SNIC) 354 through the Uppsala Multidisciplinary Center for Advanced Computational Science (UPPMAX). 


\section{References}

359 Avril A., Purcell J., Béniguel S., Chapuisat M. 2020. Maternal effect killing by a supergene controlling ant social organization. Proc Natl Acad Sci USA. 117:17130-17134.

Bailey J.A., Baertsch R., Kent W.J., Haussler D., Eichler E.E. 2004. Hotspots of mammalian chromosomal evolution. Genome Biology::7.

Baker R., Bickham J. 1986. Speciation by monobrachial centric fusions. Proc Natl Acad Sci USA. 83:8245-8248.

Barra V., Fachinetti D. 2018. The dark side of centromeres: types, causes and consequences of structural abnormalities implicating centromeric DNA. Nat Commun. 9:4340.

Barton N.H. 1979. Gene flow past a cline. Heredity. 43:333-339.

Bickham J., Baker R. 1979. Canalization model of chromosomal evolution. Bulletin of Carnegie Museum of Natural History.

Bidau C.J., Giménez M.D., Palmer C.L., Searle J.B. 2001. The effects of Robertsonian fusions on chiasma frequency and distribution in the house mouse (Mus musculus domesticus)

Bidau C.J., Martí D.A. 2002. Geographic distribution of Robertsonian fusions in Dichroplus pratensis (Melanoplinae, Acrididae): the central-marginal hypothesis reanalysed.

Bush G.L., Case S.M., Wilson A.C., Patton J.L. 1977. Rapid speciation and chromosomal evolution in mammals. Proc Natl Acad Sci USA. 74:3942-3946. 
378 Castillo E.R., Marti D.A., Bidau C.J. 2010. Sex and neo-sex chromosomes in Orthoptera: a

379 review. J Orthoptera Res. 19:213-231.

380 Charlesworth B., Lande R., Slatkin M. 1982. A neo-Darwinian comentary on macroevolution.

$381 \quad$ Evolution. 36:474-498.

382 Cigliano M., Braun H., Eades D., Otte D. 2021. Orthoptera Species File. Available from 383 http://Orthoptera.SpeciesFile.org.

384 Coyne J.A. 1984. Correlation between heterozygosity and rate of chromosome evolution in 385

Coyne J.A., Allen Orr H. 1998. The evolutionary genetics of speciation. Phil Trans R Soc Lond 387

Coyne J.A., Meyers W., Crittenden A.P., Sniegowski P. 1993. The fertility effects of pericentric inversions in Drosophila melanogaster. Genetics. 134:487-496.

Coyne J.A., Orr H.A. 2004. Speciation. Sunderland, Mass: Sinauer Associates.

Dobzhansky T. 1933. On the sterility of the Interracial hybrids in Drosophila pseudoobscura. Proc Natl Acad Sci USA. 19:397-403.

Eldredge N., Gould S. 1972. Punctuated Equilibria: An Alternative to Phyletic Gradualism. $82-15$. 
397 Faria R., Navarro A. 2010. Chromosomal speciation revisited: rearranging theory with pieces of evidence. Trends in Ecology \& Evolution. 25:660-669.

Futuyma D.J., Mayer G.C. 1980. Non-allopatric speciation in animals. Syst Biol. 29:254-271.

400

Grant V. 1981. Plant speciation. New York: Columbia University Press.

401 Gregory T.R. 2021. Animal Genome Size Database. Available from

402 http://www.genomesize.com.

403

404

405

406

407

408

409

410

411

412

413

414

415

Hoffmann A.A., Rieseberg L.H. 2008. Revisiting the impact of inversions in evolution: from population genetic markers to drivers of adaptive shifts and speciation? Annu Rev Ecol Evol Syst. 39:21-42.

Hooper D.M., Price T.D. 2015. Rates of karyotypic evolution in Estrildid finches differ between island and continental clades. Evolution. 69:890-903.

Kawakami T., Butlin R.K., Adams M., Saint K.M., Paull D.J., Cooper S.J.B. 2009. Reexamination of a proposed case of stasipatric speciation: phylogeography of the Australian morabine grasshoppers (Vandiemenella viatica species group). Mol Ecol. $18: 3429-3442$.

King M. 1985. The canalization model of chromosomal evolution: a critique. Syst Zool. 34:69_ 75.

King M. 1995. Species evolution: the role of chromosome change. London: Cambridge University Press. 
416 Kirkpatrick M., Barton N. 2006. Chromosome inversions, local adaptation and speciation. Genetics. 173:419-434.

Lande R. 1985. The fixation of chromosomal rearrangements in a subdivided population with local extinction and colonization. Heredity. 54:323-332.

421 Martí E., Milani D., Bardella V.B., Albuquerque L., Song H., Palacios-Gimenez O.M., Cabralde-Mello D.C. 2021. Cytogenomic analysis unveils mixed molecular evolution and recurrent chromosomal rearrangements shaping the multigene families on Schistocerca

425 Mayr E. 1970. Populations, species, and evolution: an abridgment of animal species and grasshopper genomes. Evolution.:evo.14287.

Milani D., Bardella V.B., Ferretti A.B.S.M., Palacios-Gimenez O.M., Melo A. de S., Moura R.C., Loreto V., Song H., Cabral-de-Mello D.C. 2018. Satellite DNAs unveil clues about transposable elements populate Eyprepocnemis plorans genome. Genetica. 140:365-374.

432 Palacios-Gimenez O.M., Bueno D., Cabral-de-Mello D.C. 2014. Chromosomal mapping of two reveals enrichment in euchromatin. European Journal of Entomology. 111:329-334. 
435 Palacios-Gimenez O.M., Carvalho C.R., Ferrari Soares F.A., Cabral-De-Mello Cabral-de-mello D.C. 2015. Contrasting the chromosomal organization of repetitive DNAs in two Gryllidae crickets with highly divergent karyotypes. PLoS ONE. 10:1-18.

438

Ruiz-Ruano F.J., López-León M.D., Cabrero J., Camacho J.P.M. 2016. High-throughput analysis of the satellitome illuminates satellite DNA evolution. Sci Rep. 6:28333-28333.

452 Saez F. a. 1957. An Extreme Karyotype in an Orthopteran Insect. The American Naturalist.

Palacios-Gimenez O.M., Milani D., Song H., Marti D.A., López-León M.D., Ruiz-Ruano F.J., Camacho J.P.M., Cabral-de-Mello D.C. 2020b. Eight Million Years of Satellite DNA Evolution in Grasshoppers of the Genus Schistocerca Illuminate the Ins and Outs of the Library Hypothesis. Genome Biol Evol. 12:88-102.

R Core Team. 2018. R: a language and environment for statistical computing. Available from https://www.R-project.org/.

Rieseberg L.H. 2001. Chromosomal rearrangements and speciation. Trends Ecol Evol. 16:351358.

$$
91: 259-259 \text {. }
$$


454 Saez F.A., Perez-Mosquera G. 1977. Structure, behaviour and evolution of the chromosomes of

455 Dichroplus silveiraguidoi (Orthoptera: Acrididae). Genetica. 47:105-113.

456 Schemske D.W. 2000. Uderstanding the origin of species. Evolution. 54:1069-1073.

457 Schluter, D. 1998. Ecological causes of speciation. New York: Oxford University Press.

458 Sites J.W., Moritz C. 1987. Chromosomal evolution and speciation revisited. Syst Zool. 36:153.

459 Song H., Amédégnato C., Cigliano M.M., Desutter-Grandcolas L., Heads S.W., Huang Y., Otte

460 D., Whiting M.F., Amédégnato C., Cigliano M.M., Desutter-Grandcolas L., Heads S.W.,

461 Huang Y., Otte D., Whiting M.F. 2015. 300 million years of diversification: Elucidating

462 the patterns of orthopteran evolution based on comprehensive taxon and gene sampling.

$463 \quad$ Cladistics. 31:621-651.

464 Song H., Béthoux O., Shin S., Donath A., Letsch H., Liu S., McKenna D.D., Meng G., Misof B.,

465 Podsiadlowski L., Zhou X., Wipfler B., Simon S. 2020. Phylogenomic analysis sheds

466 light on the evolutionary pathways towards acoustic communication in Orthoptera. Nat

467 Commun. 11:4939.

468 Spirito, F. 2000. The role of chromosomal rearrangements in speciation. New York: Oxford $469 \quad$ University Press.

470 Stanley S.M. 1975. A theory of evolution above the species level. Proc Nat Acad Sci USA. $471 \quad 72: 646-650$. 
472 Sylvester T., Hjelmen C.E., Hanrahan S.J., Lenhart P.A., Johnston J.S., Blackmon H. 2020.

473 Lineage-specific patterns of chromosome evolution are the rule not the exception in

$474 \quad$ Polyneoptera insects. Proc. R. Soc. B. 287:20201388.

475 Tegelström H., Ebenhard T., Ryttman H. 1983. Rate of karyotype evolution and speciation in $476 \quad$ birds. Hereditas. 98:235-239.

477 Templeton A.R. 1981. Mechanisms of speciation - a population genetic approach. Annu Rev $478 \quad$ Ecol Syst. 12:23-48.

479 Walsh J.B. 1982. Rate of accumulation of reproductive isolation by chromosome 480 rearrangements. Am Nat. 120:510-532.

481 White M. 1978. Modes of Speciation. San Francisco, CA, USA: Cambridge University Press.

482 Wright S. 1931. Evolution in Mendelian Populations. Genetics. 16:97-159.

483 Wright S. 1940. Breeding structure of populations in relation to speciation. Am Nat. 74:232-248.

484 Wright S. 1949. The genetical strutue of populations. Ann Eugen. 15:323-354.

485 Ylla G., Nakamura T., Itoh T., Kajitani R., Toyoda A., Tomonari S., Bando T., Ishimaru Y., 486 Watanabe T., Fuketa M., Matsuoka Y., Barnett A.A., Noji S., Mito T., Extavour C.G. 487 2020. Insights into the genomic evolution of insects from cricket genomes. .

488 Yoshida K., Kitano J. 2021. Tempo and mode in karyotype evolution revealed by a probabilistic 489 model incorporating both chromosome number and morphology. PLoS Genet.

490 17:e1009502. 


\section{Tables}

493 Table 1: Rates of karyotype evolution in extant family of Orthoptera

\begin{tabular}{|c|c|c|c|c|}
\hline Family & $\begin{array}{l}\text { Number of } \\
\text { karyotyped species, } \\
K S\end{array}$ & $\begin{array}{l}\text { FN Shannon } \\
\text { index, } H^{\prime}\end{array}$ & $\begin{array}{l}\text { Average age of } \\
\text { the family, } \\
\text { Myr }\end{array}$ & $\begin{array}{l}\text { Karyotypic changes/ } \\
\text { lineage per Myr, } r\end{array}$ \\
\hline Trigonidiidae & 35 & 3.525 & 175 & 0.322 \\
\hline Mogoplistidae* & 1 & 0 & 200 & 0 \\
\hline Gryllotalpidae & 19 & 2.944 & 98 & 0.526 \\
\hline Gryllidae & 43 & 3.696 & 98 & 0.871 \\
\hline Phalangopsidae & 34 & 3.488 & 98 & 0.595 \\
\hline Schizodactylidae* & 1 & 0 & 215 & 0 \\
\hline Tettigoniidae & 571 & 6.341 & 115 & 0.816 \\
\hline Rhaphidophoridae & 28 & 3.297 & 215 & 0.443 \\
\hline Anostostomatidae & 27 & 3.292 & 125 & 0.478 \\
\hline Gryllacrididae & 2 & 0.670 & 150 & 0.153 \\
\hline Stenopelmatidae & 2 & 0.553 & 125 & 0.632 \\
\hline Cylindrachetidae & 2 & 0.693 & 202 & 0.103 \\
\hline Tridactylidae & 3 & 1.095 & 320 & 0.088 \\
\hline Ripipterygidae* & 1 & 0 & 153 & 0 \\
\hline Tetrigidae & 10 & 2.301 & 263 & 0.089 \\
\hline Proscopiidae & 9 & 2.193 & 167 & 0.234 \\
\hline Epistacidae & 2 & 0.693 & 167 & 0.149 \\
\hline Eumastacidae & 23 & 3.131 & 162 & 0.292 \\
\hline Morabidae & 14 & 2.633 & 162 & 0.259 \\
\hline Pyrgomorphidae & 9 & 2.197 & 147 & 0.235 \\
\hline Pamphagidae & 23 & 3.131 & 125 & 0.363 \\
\hline Lentulidae & 12 & 2.485 & 80 & 0.533 \\
\hline Tristiridae & 8 & 2.079 & 98 & 0.418 \\
\hline Acrididae & 238 & 5.475 & 80 & 0.648 \\
\hline Romaleidae & 38 & 3.637 & 80 & 0.573 \\
\hline Ommexechidae & 21 & 3.045 & 77 & 0.673 \\
\hline Average & & & & 0.365 \\
\hline
\end{tabular}


Table 2: Rates of speciation in extant family of Orthoptera

\begin{tabular}{|c|c|c|c|c|}
\hline Family & $\begin{array}{l}\text { Net } \\
\text { speciation } \\
\text { rate, } R\end{array}$ & $\begin{array}{l}\text { Mean species } \\
\text { duration time, } D\end{array}$ & $\begin{array}{l}\text { Extinction } \\
\text { rate, } E\end{array}$ & $\begin{array}{l}\text { Corrected } \\
\text { speciation } \\
\text { rate, } S\end{array}$ \\
\hline Trigonidiidae & 5.111 & 87.5 & 0.011 & 5.123 \\
\hline Mogoplistidae & 1.847 & 100.0 & 0.010 & 1.857 \\
\hline Gryllotalpidae & 1.097 & 49 & 0.020 & 1.117 \\
\hline Gryllidae & 49.862 & 49.0 & 0.020 & 49.88 \\
\hline Phalangopsidae & 3.291 & 49.0 & 0.020 & 3.311 \\
\hline Schizodactylidae & 0.072 & 77 & 0.009 & 0.081 \\
\hline Tettigoniidae & 46.133 & 57.5 & 0.017 & 46.146 \\
\hline Rhaphidophoridae & 2.391 & 107.5 & 0.009 & 2.398 \\
\hline Anostostomatidae & 1.684 & 62.5 & 0.016 & 1.700 \\
\hline Gryllacrididae & 5.057 & 75.0 & 0.013 & 5.070 \\
\hline Stenopelmatidae & 0.316 & 62.5 & 0.016 & 0.332 \\
\hline Cylindrachetidae & 0.010 & 101.0 & 0.010 & 0.020 \\
\hline Tridactylidae & 0.010 & 160.0 & 0.006 & 0.016 \\
\hline Ripipterygidae & 0.461 & 76.5 & 0.013 & 0.474 \\
\hline Tetrigidae & 6.705 & 131.5 & 0.008 & 6.713 \\
\hline Proscopiidae & 1.596 & 83.5 & 0.012 & 1.608 \\
\hline Epistacidae & 0.404 & 83.5 & 0.012 & 0.416 \\
\hline Eumastacidae & 1.410 & 81.0 & 0.012 & 1.423 \\
\hline Morabidae & 0.991 & 81.0 & 0.012 & 1.003 \\
\hline Pyrgomorphidae & 3.221 & 73.5 & 0.014 & 3.235 \\
\hline Pamphagidae & 3.628 & 62.5 & 0.016 & 3.644 \\
\hline Lentulidae & 1.269 & 40.0 & 0.025 & 1.294 \\
\hline Tristiridae & 0.260 & 49.0 & 0.020 & 0.280 \\
\hline Acrididae & 82.994 & 40.0 & 0.025 & 83.019 \\
\hline Romaleidae & 0.481 & 40.0 & 0.025 & 0.506 \\
\hline Ommexechidae & 0.435 & 38.5 & 0.026 & 0.461 \\
\hline Average & 8.490 & 76.6 & 0.015 & 8.505 \\
\hline
\end{tabular}


Figures

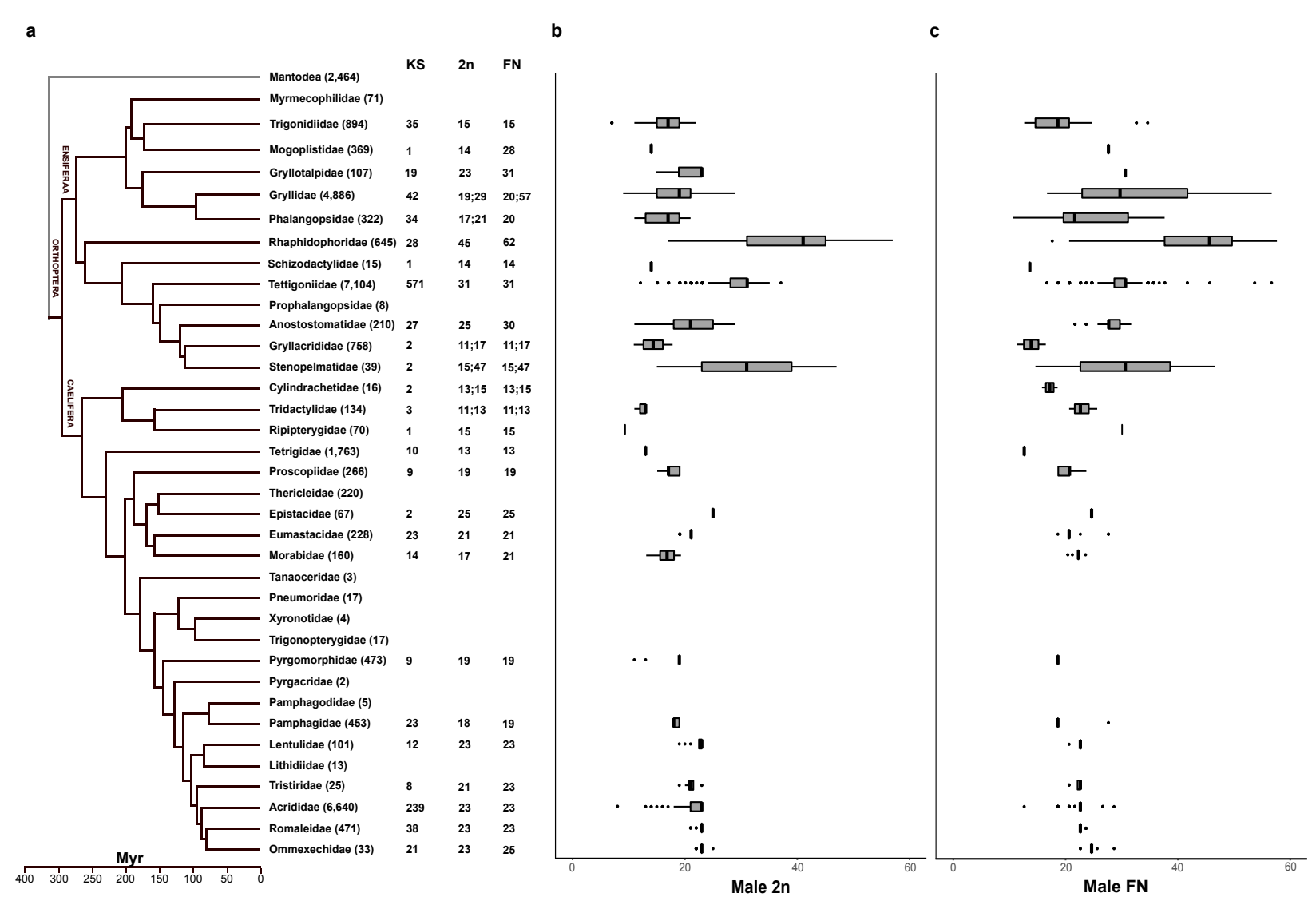

Figure 1: Karyotype and fundamental number distributions across the orthoptera phylogeny. a Dated phylogeny of Orthoptera based on phylogenomic data (Song et al. 2015, 2020). Each terminal represents a monophyletic family and the number in parenthesis next to the family name indicates the number of validly described species within the family. The number of karyotyped species (KS), the most common diploid number (2n) and most common fundamental number (FN) in males are showed for the 25 analysed families. b and c Boxplots showing the distribution of both the diploid number $(2 n)$ and the fundamental number (FN) in males across each family analysed. Myr= millions of years ago. 


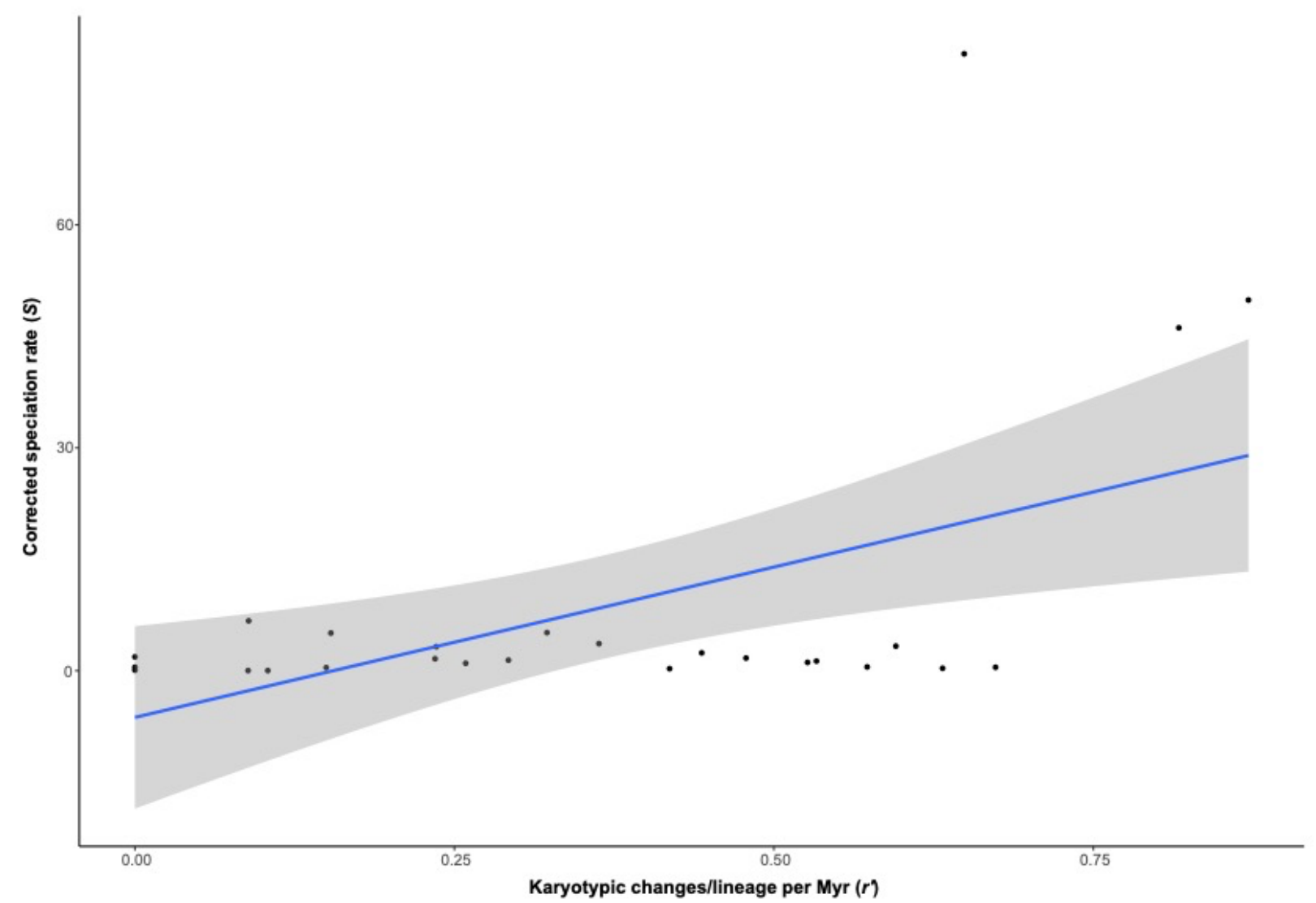

515 Figure 2. Linear regression showing the relationship between corrected speciation rate $(S)$ and 516 rate of karyotypic changes $\left(r{ }^{\prime}\right)$ for the 26 families of Orthoptera analysed $(P=0.00596)$. Myr= 517 million years. 